\title{
28 Research Square \\ Spectroscopic sensing of eight metal ions in aqueous solutions using silver nanoparticles
}

\section{Selvaraj Tamilselvan}

Sathyabama Institute of Science and Technology

Rathnavelu Murali Soniya

Sri Venkateswara College of Pharmacy

Raguraman Vasantharaja

Sathyabama Institute of Science and Technology

Malaichamy Kannan

Tamil Nadu Agricultural University

Subrahmanian Supriya

Sathyabama Institute of Science and Technology

Kasivelu Govindaraju ( $\sim$ govindtu@gmail.com )

Sathyabama Institute of Science and Technology https://orcid.org/0000-0002-9687-2174

\section{Research Article}

Keywords: Silver nanoparticles, Heavy metal ions, UV-vis spectroscopy, FT-IR spectroscopy, sensing

Posted Date: February 1st, 2022

DOI: https://doi.org/10.21203/rs.3.rs-1246304/v1

License: (c) (i) This work is licensed under a Creative Commons Attribution 4.0 International License.

Read Full License 


\section{Abstract}

Anthropogenic releases from different outlets of industry, municipal sewage and the road traffic can give rise to higher concentrations of the heavy metals in the food commodities which imposes a threat to human health and environment. A simple silver nanoparticle (Ag NPs) used for the sensing of heavy metal ions, $\mathrm{Cd}^{2+}, \mathrm{Cu}^{2+}, \mathrm{Fe}^{2+}, \mathrm{Hg}^{2+}, \mathrm{Mn}^{2+}, \mathrm{Ni}^{2+}, \mathrm{Pb}^{2+}$ and $\mathrm{Zn}^{2+}$ in aqueous solution is described by qualitative and quantitatively using spectroscopic tool. FE-SEM and TEM images confirmed that the particles are spherical in shape with an average diameter of $23.4 \mathrm{~nm}$. In presence of heavy metal ions with Ag NPs, a new peak at around 925, 898, 643, 665, 688, and $838 \mathrm{~nm}$ of $\mathrm{Cd}^{2+}, \mathrm{Cu}^{2+}, \mathrm{Fe}^{2+}, \mathrm{Hg}^{2+}, \mathrm{Mn}^{2+}$ and $\mathrm{Zn}^{2+}$ appeared in addition to the peak found at $410 \mathrm{~nm}$ of Ag NPs. Further, the addition of $\mathrm{Ni}^{2+}$ and $\mathrm{Pb}^{2+}$ metal ion solution with Ag NPs increased the SPR band from $410 \mathrm{~nm}$ to 436 and $462 \mathrm{~nm}$ respectively. Citrate functionalized Ag NPs are aggregated in solution in the presence of divalent metal ions by an ions-template chelating process and easily measurable change in the UV-vis absorption spectrum of the particles. Further, studies also confirmed the interaction of Ag NPs with metal ions using FT-IR spectroscopy. The proposed method was found to be useful for simple UV-vis spectroscopic sensing of metal ions in aqueous solutions and real contaminated samples.

\section{Introduction}

Heavy metals are commonly defined as elements that have a density at least 5 times higher than of water. Their presence in the soil can be of natural and anthropogenic origin. Due to natural processes in the earth's crust, the soil usually contains low concentrations of heavy metals. However, different anthropogenic activities lead to an increase of heavy metals concentration above the natural level in aquatic ecosystems. As heavy metals are not biodegradable, they accumulate in the environment and enter the food chain as bioaccumulation. Further, excessive intake of heavy metals into living organisms causes many harmful consequences, including death (Zwolak et al. 2019). Various heavy metals such as $\mathrm{Cd}^{2+}, \mathrm{Cu}^{2+}, \mathrm{Fe}^{2+}, \mathrm{Hg}^{2+}, \mathrm{Mn}^{2+}, \mathrm{Ni}^{2+}, \mathrm{Pb}^{2+}$ and $\mathrm{Zn}^{2+}$ are reported to be potential environmental pollutants and causing various problems such soil, aquatic organisms, plants, animals and human at trace ppm level concentrations (Sheet et al. 2014; Fajardo et al. 2019). So far, quite a few reports are available for the detection/sensing of metal ions using various analytical techniques (Nolan and Lippard 2008; Ray 2010; Aragay et al. 2011; Singh et al. 2021) and conventional methods for heavy metal quantitative measurement include atomic absorption spectroscopy (AAS), atomic fluorescence spectrometry (AFS), inductively coupled plasma mass spectrometry (ICP-MS) and electrochemical sensing platforms (Kumeria et al. 2013) offer excellent sensitivity, multi-element analysis but, they are high expensive, time consuming, skill dependent and use non-portable accessories.

In recent years, nanomaterials-based sensing/detection of metal ions due to their optical properties with high extinction co-efficient at the visible region for improving the performance of sensors in terms of sensitivity, limit of detection, selectivity and reproducibility (Zheng et al. 2004; Prosposito et al. 2020; Wang et al. 2020). So far, several reports are available for the sensing/detection of toxic metal ions using 
various synthetic (biogenic, physical and chemical) methods. For instance, Kim et al (2001) reported the sensing of spectroscopically silent heavy metal ions $\left(\mathrm{Pb}^{2+}\right)$ using 11-mercaptoundecanoic acid stabilized gold nanoparticles. Wang et al (2010) reported the detection of $\mathrm{Hg}^{2+}$ ions using unmodified silver nanoparticles and mercury specific oligonucleotides used as sensors (Zheng et al. 2004). Green synthesized silver nanoparticles using aqueous extract of Hedysarum alpinum plant used for calorimetrically detection of $\mathrm{Hg}^{2+}$. Zhou et al (2012) reported silver nanoparticles co-functionalized with 4-mercapto benzoic acid and melamine as a probe for colorimetric detection of $\mathrm{Mn}^{2+}$. Green synthesis of L-tyrosine-stabilized silver nanoparticles under ambient sunlight irradiation for colorimetric detection of heavy metal ions $\left(\mathrm{Hg}^{2+}\right.$ and $\left.\mathrm{Pb}^{2+}\right)$ as reported. Recently, Wang et al (2020) reported that the carrageenan stabilized silver nanoparticles for effective detection of $\mathrm{Cu}^{2+}$ and $\mathrm{S}^{2-}$ ions in aqueous solution. In the present investigation, sodium citrate stabilized silver nanoparticles for sensing/detection of various metal ions $\left(\mathrm{Cd}^{2+}, \mathrm{Cu}^{2+}, \mathrm{Fe}^{2+}, \mathrm{Hg}^{2+}, \mathrm{Mn}^{2+}, \mathrm{Ni}^{2+}, \mathrm{Pb}^{2+}\right.$ and $\left.\mathrm{Zn}^{2+}\right)$ in aqueous solution using UV-vis spectroscopic technique. Further, metal ion interactions with silver nanoparticles were studied using FT-IR spectroscopy.

\section{Materials And Methods}

\section{Synthesis of Ag NPs}

Synthesis of silver nanoparticles using sodium citrate as reducing agents was done according to the literature procedure (Kamat et al. 1998) with slight modification. Briefly, $100 \mathrm{~mL}$ of $\mathrm{AgNO}_{3}(10 \mathrm{mg})$ aqueous solution and heated until it begins to boil. $2 \mathrm{~mL}$ of sodium citrate ( $30 \mathrm{mg}$ ) solution was added, and heating continued till the color was yellowish brown color which indicates formation of Ag NPs nanoparticles.

\section{Characterization of Ag NPs}

The formation of Ag NPs was monitored using a UV-visible spectrophotometer (Shimadzu UV-1800) in the range of 200-1000 nm. Particle's size and shape of the citrate reduced Ag NPs were determined using FE-SEM (Supra 55-Carl Zeiss, Germany) and TEM (FEI Technai, instruments) operating at an accelerating voltage of 120kVA.

\section{Sensing/ detection of Metal ions}

The spectroscopic detection of aqueous heavy metal ions was studied using Ag NPs solution at room temperature. To demonstrate the effect of heavy metal ions on Ag NPs,

$1 \mathrm{~mL}$ concentrations of heavy metal ions were added one at a time to $500 \mu \mathrm{L}$ of Ag NPs and the resulting mixture was then allowed to stand for $10 \mathrm{~min}$ at room temperature, during which the colour change depending upon the metal ions. The intensity of this colour gradually increased with the increase of heavy metal ion concentration. UV-Vis absorption spectra from all samples were analyzed carefully to correlate the changes of SPR spectra with respect to concentrations of $\mathrm{Cd}^{2+}, \mathrm{Cu}^{2+}, \mathrm{Fe}^{2+}, \mathrm{Hg}^{2+}, \mathrm{Mn}^{2+}, \mathrm{Ni}^{2+}$, $\mathrm{Pb}^{2+}$ and $\mathrm{Zn}^{2+}$ using UV-visible Spectrophotometer (UV 1800) Shimadzu, Japan. Spectra of the 
adsorbents before and after $\mathrm{Cd}^{2+}, \mathrm{Cu}^{2+}, \mathrm{Fe}^{2+}, \mathrm{Hg}^{2+}, \mathrm{Mn}^{2+}, \mathrm{Ni}^{2+}, \mathrm{Pb}^{2+}$ and $\mathrm{Zn}^{2+}$ binding were recorded with a FT-IR analysis using a PerkinElmer 1600 infra-red spectrometer with a pellet of powered potassium bromide.

\section{Results And Discussion}

Addition of sodium citrate into the beakers containing aqueous solution of $\mathrm{AgNO}_{3}$ led to the change in the colour of the solution from colorless to brownish yellow within reaction duration due to excitation of surface plasmon resonance (SPR) vibrations in Ag NPs. The colour of the solution is brownish yellow indicating formation of Ag NPs (Figure 1 inset). Ag NPs synthesized using sodium citrate were analyzed by UV spectra of Plasmon resonance band observed at $410 \mathrm{~nm}$ (Figure 1) (Zia et al. 2016). SEM micrograph shows the morphology of the Ag NPs which are spherical and well dispersed (Figure 2a). TEM results showed well dispersed spherical particles with a size of ca. $23.4 \mathrm{~nm}$ in diameter (Figure $2 b \& c)$.

The spectroscopic detection of metal ions $\mathrm{Cd}^{2+}, \mathrm{Cu}^{2+}, \mathrm{Fe}^{2+}, \mathrm{Hg}^{2+}, \mathrm{Mn}^{2+}, \mathrm{Ni}^{2+}, \mathrm{Pb}^{2+}$ and $\mathrm{Zn}^{2+}$ at the fixed concentrations of $500 \mu \mathrm{L}$ of a $1 \times 10^{-5} \mathrm{M}$ were added to Ag NPs solution and the corresponding changes of the absorption coefficient were observed from brownish yellow to light blue color (Figure 3a-h) (Kamel et al. 2019; Boruah et al. 2019). In presence of heavy metal ions with Ag NPs, a new peak at around 925, $898,643,665,688$, and $838 \mathrm{~nm}$ of $\mathrm{Cd}^{2+}, \mathrm{Cu}^{2+}, \mathrm{Fe}^{2+}, \mathrm{Hg}^{2+}, \mathrm{Mn}^{2+}$ and $\mathrm{Zn}^{2+}$ appeared in addition to the peak found at $410 \mathrm{~nm}$ of Ag NPs (Figure 4a-e, h). Further, the addition of $\mathrm{Ni}^{2+}$ and $\mathrm{Pb}^{2+}$ metal ion solution with Ag NPs increased the SPR band from $410 \mathrm{~nm}$ to 436 and $462 \mathrm{~nm}$ respectively (Figure 4f, 4g). Even though Pb interacts with Ag NPs surface plasmon resonance (SPR) peak at 436 near to Ag NPs similar reported (Anambiga et al. 2013). Ag NPs undergo agglomeration upon exposure to increasing concentrations of heavy metal ions. Color change occurred due to the aggregation between Ag NPs with metal ions (Xiong and Li 2008). The ability of silver nanoparticles to form agglomeration caused the SPR to broaden and shift to longer wavelengths (Sulistiawaty et al. 2015). In particular $\mathrm{Hg}^{2+}$ ions interact with Ag NPs precipitation and the SPR band absorbance at $410 \mathrm{~nm}$. Besides, the colour of the Ag NPs became transparent immediately when added to the $\mathrm{Hg}^{2+}$ ions solution. In contrast, increasing the concentration of $\mathrm{Ag} \mathrm{NPs}$ to $\mathrm{Hg}^{2+}$ solution changed colour into yellow precipitate (Uddin et al. 2017). Similarly, the Ag NPs were interacting with $\mathrm{Hg}^{2+}$ and $\mathrm{Mn}^{2+}$ ions, a blue shift in the SPR band was observed by UV-vis spectroscopy detection. $\mathrm{Hg}^{2+}$ ions were added to the Ag NPs solution and the colour of the solution changed from yellow to colorless. This interaction is due to oxidation of $\mathrm{Ag}^{0}$ to $\mathrm{Ag}^{+}$during the process of reduction of $\mathrm{Hg}^{2+}$ ions (Annadhasan et al. 2014).

FT-IR measurements were carried out to identify the interaction of Ag NPs and metal ions. FT-IR spectra of Ag NPs functional groups 2924, 2856, 2338, 1714, $1638 \mathrm{~cm}^{-1}$ respectively, $\mathrm{CdSO}_{4}$ and $\mathrm{CdSO}_{4}+\mathrm{Ag} \mathrm{NPs}$ show several significant absorption peaks such as 2956, 2128, 1638 and 2327, $1639 \mathrm{~cm}^{-1}$ disappears in $\mathrm{CdSO}_{4}+$ Ag NPs. The peaks 2338 shifted into 2339 (Figure. 5a-c). FT-IR spectra of Ag NPs, $\mathrm{CuSO}_{4}, \mathrm{CuSO}_{4}$ 
+ Ag NPs, absorption peaks at 2924, 2855 and 2448, $2092 \mathrm{~cm}^{-1}$ were disappeared in $\mathrm{CuSO}_{4}+\mathrm{AgNPs}$ and new peaks at 2956 shifted into 2969, 1737 shifted into 1738 (Figure 6). Similar study of FeO nanoparticles observation confirms a successful modification of the surface of the nanoparticles with $\mathrm{Cd}$ and $\mathrm{Cu}$ ions (Klekotka et al. 2018). There were significant changes on the FT-IR spectrum of Ag NPs after interaction with $\mathrm{FeSO}_{4}$ ions. The Ag NPs and $\mathrm{FeSO}_{4}$ absorption peaks at 2956, 2855, 2338, 2128, 1714, 2326, $1642 \mathrm{~cm}^{-1}$ were appearing but disappeared in the $\mathrm{FeSO}_{4}+\mathrm{Ag}$ NPs whereas new peaks appeared at 2926, besides the peak at 2924 shifted into 2916 (Figure 7). The FT-IR spectrum of Ag NPs, $\mathrm{HgCl}_{2}$ and $\mathrm{HgCl}_{2}+\mathrm{Ag}$ NPs was represented in Figure 8. The presence of a sharp absorption band at 2956, 2125, 2188 and $2097 \mathrm{~cm}^{-1}$ in Ag NPs and $\mathrm{HgCl}_{2} . \mathrm{HgCl}_{2}+$ Ag NPs new peak 2855, 1737 shifted into 2853, 1738 . FT-IR spectral data revealed absorption peaks at 2956, 2338, 2128, 1737, 1714 and $2199 \mathrm{~cm}^{-1}$ were present in Ag NPs and $\mathrm{MnCl}_{2}$. Whereas the peak at 2855, 1638 shifted into 2853, 1640 present in $\mathrm{MnCl}_{2}+$ Ag NPs (Figure. 9). FT-IR spectra of $\mathrm{Ag} \mathrm{NPs} \mathrm{NiSO}_{4}$ and $\mathrm{NiSO}_{4}+\mathrm{Ag} \mathrm{NPs}$ based on the functional groups 2924, 2856, 2338, 1714, $1638 \mathrm{~cm}^{-1}$ and 3293, 2332, $1638 \mathrm{~cm}^{-1}$ peaks were present and 2332, 2128, $1714,1638 \mathrm{~cm}^{-1}$ peaks were disappeared in Ag NPs and $\mathrm{NiSO}_{4}$. While 3459, 3016, 2132 and $1434 \mathrm{~cm}^{-1}$ peaks were present in $\mathrm{NiSO}_{4}+\mathrm{Ag} \mathrm{NPs.} 2128 \mathrm{~cm}^{-1}$ line is observed in p-polarization and is absent in spolarization shifted into $2132-\mathrm{C} \equiv \mathrm{C}-$ stretch and the presence of a broad absorption band at 3392 and $3459 \mathrm{~cm}^{-1}$ can be attributed the $-\mathrm{OH}$ stretching presented due to the adsorption of water in air when FT-IR sample disks were prepared in an open air (Figure 10). FT-IR analysis on Ag NPs, $\mathrm{Pb}(\mathrm{NO})_{3}$ and $\mathrm{Pb}(\mathrm{NO})_{3}+$ Ag NPs reveals that the peaks at 2956, 2924, 2855, 2338, 2398 and $1768 \mathrm{~cm}^{-1}$ were present [Ag NPs, $\left.\mathrm{Pb}(\mathrm{NO})_{3}\right]$ but disappear in the $\mathrm{Pb}(\mathrm{NO})_{3}+\mathrm{Ag} \mathrm{NPs}$. The broad absorption peak 2128,1638 shifted into $2125 \mathrm{~cm}^{-1}, 1654 \mathrm{~cm}^{-1}$ confirms the formation of Pb-Ag NPs complex (Figure 11) (Kamel et al. 2019; Anambiga et al. 2013). FT-IR absorption peaks at 2128, 1714 and $1616 \mathrm{~cm}^{-1}$ were present in Ag NPs and $\mathrm{ZnSO}_{4}$ whereas disappear in $\mathrm{ZnSO}_{4}+\mathrm{Ag} \mathrm{NPs}$. A ZnSO 4 + Ag NPs new peak appears at 2871 and 1980.

The peaks were 2338, 2077 and $1737 \mathrm{~cm}^{-1}$ shifted into 2340, 2079 and $1741 \mathrm{~cm}^{-1}$ (Figure 12). Based on the present study and previous literature report, the conceivable predicted mechanisms of Ag NPs interaction with metal ions which is shown in Figure 13.

\section{Conclusions}

Herein, we report the Ag NPs as a cost-effective sensor for the detection of toxic metal ions in water. The spectroscopic tool such as UV-vis spectroscopy was used for detection and of various heavy metal ions $\left(\mathrm{Cd}^{2+}, \mathrm{Cu}^{2+}, \mathrm{Fe}^{2+}, \mathrm{Hg}^{2+}, \mathrm{Mn}^{2+}, \mathrm{Ni}^{2+}, \mathrm{Pb}^{2+}\right.$ and $\left.\mathrm{Zn}^{2+}\right)$ in aqueous medium with the detection limits of $\mathrm{nM}$ concentrations and easily visualized with the naked eye by the rapid color change from a brownish yellow to light blue color observed. From the noteworthy mention that spectral changes and fast colour changes of ions with the addition of nanoparticles, we conclude that ions can potentially become a selective detection for the qualitative detection of the used nanoparticles and could be used as a visual marker.

\section{Declarations}


Acknowledgements

The authors (KG) thankful to the DST-FIST (SR/FST/ESI-145/2016) for infrastructure support to carry out this work and management of Sathyabama Institute of Science and Technology, Chennai for their constant support in research activities.

Ethics approval and consent to participate Not applicable.

Consent to Participate Not applicable.

Consent to Publish Not applicable.

Authors contribution S. Tamilselvan: Methodology, Investigation, Validation; R.M. Soniya: Investigation, Formal analysis, Data curation; R. Vasantharaja: Formal analysis, Review \& editing; M. Kannan: Validation, Resources, Writing - review \& editing; S. Supriya: Formal analysis, Resources; K. Govindaraju: Conceptualization, Project administration, Writing - review \& editing.

Funding Not applicable.

Competing interests The authors declare no competing interests.

Availability of data and materials The datasets used and/or analyzed during the current study are available from the corresponding author on reasonable request.

\section{References}

1. Anambiga IV, Suganthan V, Raj NAN, Kumar TSS (2013) Colorimetric detection of lead ions using glutathione stabilized silver nanoparticles. Int J Sci Eng Res 4:710-715

2. Annadhasan M, Muthukumarasamyvel T, Sankar Babu VR, Rajendiran N (2014) Green Synthesized silver and gold nanoparticles for colorimetric detection of $\mathrm{Hg}^{2+}, \mathrm{Pb}^{2+}$ and $\mathrm{Mn}^{2+}$ in aqueous medium. ACS Sustainable Chem Eng 2:887-896

3. Aragay G, Pons J, Merkoci A (2011) Recent trends in macro-micro and nanomaterial based tools and strategies for heavy metal detection. Chem Rev 111:3433-3458

4. Boruah BS, Daimari NK, Biswas R (2019) Functionalized silver nanoparticles as an effective medium towards trace determination of arsenic (III) in aqueous solution. Results in Phys 12:2061-2065

5. Fajardo C, Costa G, Nande M, Martin C, Martin M, Sanchez-Fortun S (2019) Heavy metals immobilization capability of two iron-based nanoparticles ( $\mathrm{nZVI}$ and $\mathrm{Fe}_{3} \mathrm{O}_{4}$ ): Soil and freshwater bioassays to assess ecotoxicological impact. Sci Total Environ 656:421-432

6. Kamat PV, Flumiani M, Hartland GV (1998) Picosecond dynamics of silver nanoclusters. photoejection of electrons and fragmentation. J Phys Chem B 102:3123-3128

7. Kamel GM, El-Nahass MN, El-Khouly ME, Fayed TA, El-Kemary M (2019) Simple, selective detection and efficient removal of toxic lead and silver metal ions using Acid Red 94. RSC Adv 9:8355-8363 
8. Kim Y, Johnson RC, Hupp JT (2001) Gold nanoparticle-based sensing of "spectroscopically silent" heavy metal ions. Nano Lett 1:165-167

9. Klekotka U, Winska E, Zambrzycka-Szelewa E, Satuła D, Kalska-Szostko B (2018) Heavy-metal detectors based on modified ferrite nanoparticles. Beilstein J Nanotechnol 9:762-770

10. Kumeria T, Santos A, Losic D (2013) Ultrasensitive nanoporous interferometric sensor for label-free detection of gold(III) ions. ACS Appl Mater Interf 5:11783-11790

11. Nolan EM, Lippard SJ (2008) Tools and tactics for the optical detection of mercuric ion. Chem Rev 108:3443-3480

12. Prosposito P, Burratti L, Venditti I (2020) Silver nanoparticles as colorimetric sensors for water pollutants. Chemosensors 8:26

13. Ray PC (2010) Size and shape dependent second order nonlinear optical properties of nanomaterials and their application in biological and chemical sensing. Chem Rev 110:5332-5365

14. Sheet I, Kabbani A, Holail H (2014) Removal of heavy metals using nanostructured graphite oxide, silica nanoparticles and silica/graphite oxide composite. Energy Procedia 50:130-138

15. Singh H, Bamrah A, Bhardwaj SK, Deep A, Khatri M, Brown RJC, Bhardwaj N, Kim KH (2021) Recent advances in the application of noble metal nanoparticles in colorimetric sensors for lead ions. Environ Sci Nano 8:863-889

16. Sulistiawaty L, Sugiarti S, Darmawan N (2015) Detection of $\mathrm{Hg}^{2+}$ metal ions using silver nanoparticles stabilized by gelatin and tween-20. Indonesian J Chem 15:1-8

17. Uddin I, Ahmad K, Khan AA, Kazmi MA (2017) Synthesis of silver nanoparticles using Matricaria recutita (Babunah) plant extract and its study as mercury ions sensor. Sensing and Bio-Sensing Res 16:62-67

18. Wang Y, Dong X, Zhao L, Xue Y, Zhao X, Li Q, Xia Y (2020) Facile and green fabrication of carrageenan-silver nanoparticles for colorimetric determination of $\mathrm{Cu}^{2+}$ and $\mathrm{S}^{2-}$. Nanomaterials 10:83

19. Wang $Y$, Yang F, Yang $X$ (2010) Colorimetric detection of mercury (II) ion using unmodified silver nanoparticles and mercury-specific oligonucleotides. ACS Appl Mater Interf 2:339-342

20. Xiong D, Li H (2008) Colorimetric detection of pesticides based on calixarene modified silver nanoparticles in water. Nanotechnology 19:465502

21. Zheng J, Zhang C, Dickson RM (2004) Highly fluorescent, water-soluble, size-tunable gold quantum dots. Phys Rev Lett 93:077402

22. Zhou Y, Zhao H, Li C, He P, Peng W, Yuan L, Zeng L, He Y (2012) Colorimetric detection of $\mathrm{Mn}^{2+}$ using silver nanoparticles cofunctionalized with 4-mercaptobenzoic acid and melamine as a probe. Talanta 97:331-335

23. Zia F, Ghafoor N, Iqbal M, Mehboob S (2016) Green synthesis and characterization of silver nanoparticles using Cydonia oblong seed extract. Appl Nanosci 6:1023-1029 
24. Zwolak A, Sarzyńska M, Szpyrka E, Stawarczyl K (2019) Sources of soil pollution by heavy metals and their accumulation in vegetables: A review. Water Air Soil Poll 230:164

\section{Figures}

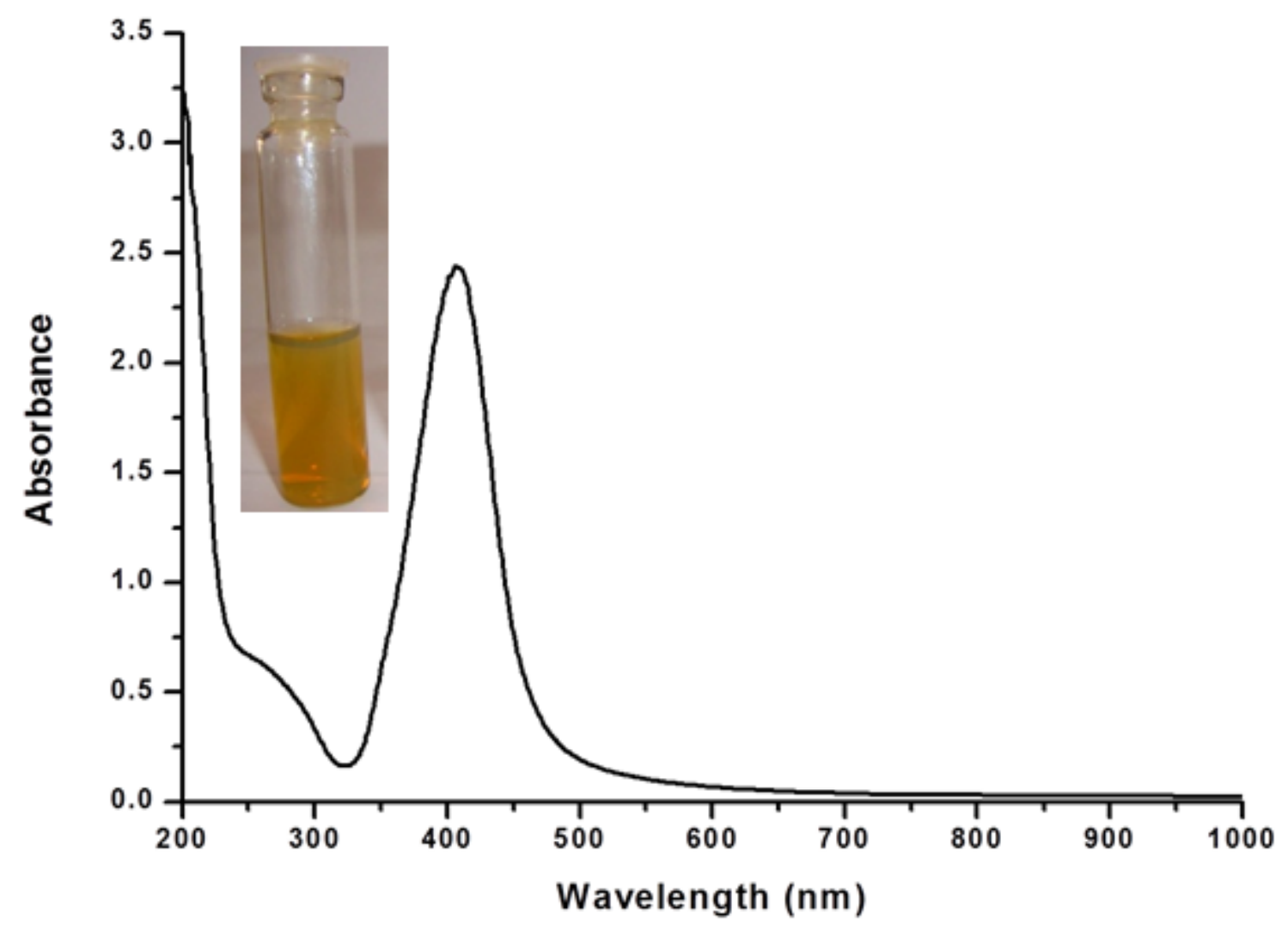

Figure 1

UV-Vis spectra of sodium citrate mediated synthesized Ag NPs. Inset shows citrate mediated synthesized Ag NPs. 

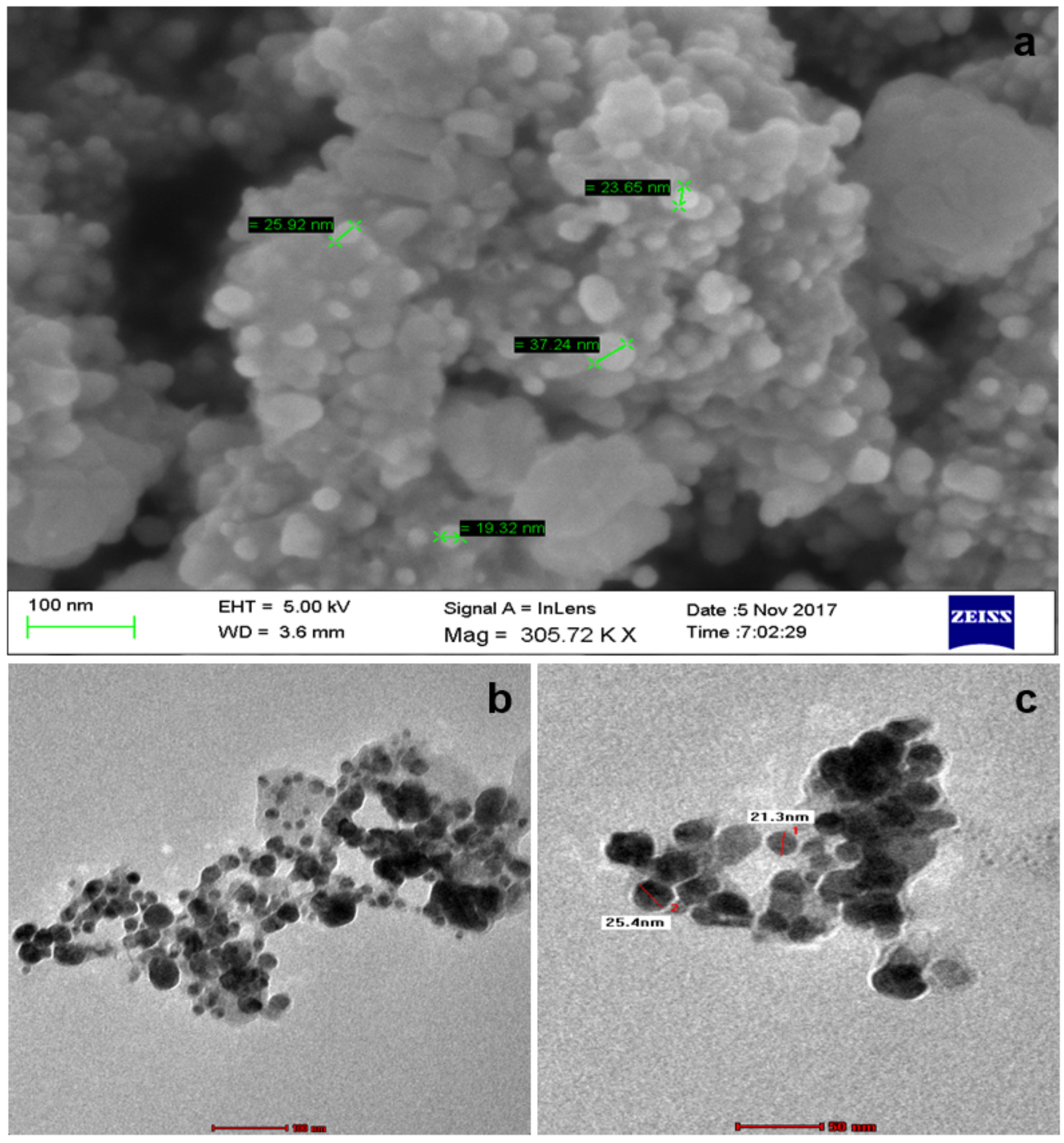

Figure 2

a) SEM image; b\&c) TEM images of sodium citrate mediated synthesized Ag NPs. 

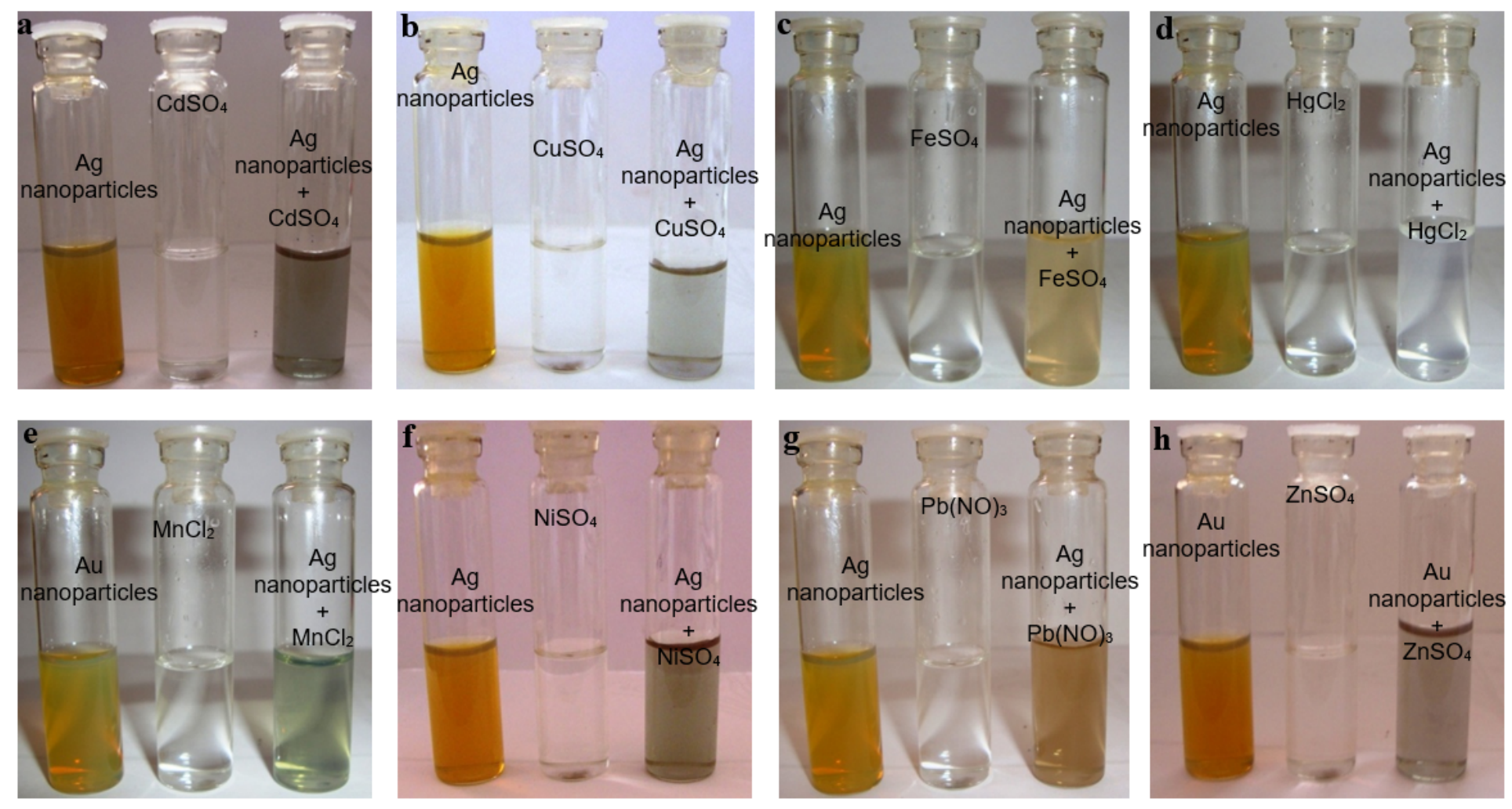

Figure 3

Photograph showing the visual observation of before and after addition of Ag NPs with metal ions solutions (a) $\mathrm{Cd}^{2+}$, (b) $\mathrm{Cu}^{2+}$, (c) $\mathrm{Fe}^{2+}$, (d) $\mathrm{Hg}^{2+}$, (e) $\mathrm{Mn}^{2+}$, (f) $\mathrm{Ni}^{2+}$, (g) $\mathrm{Pb}^{2+}$ and (h) $\mathrm{Zn}^{2+}$ ions 

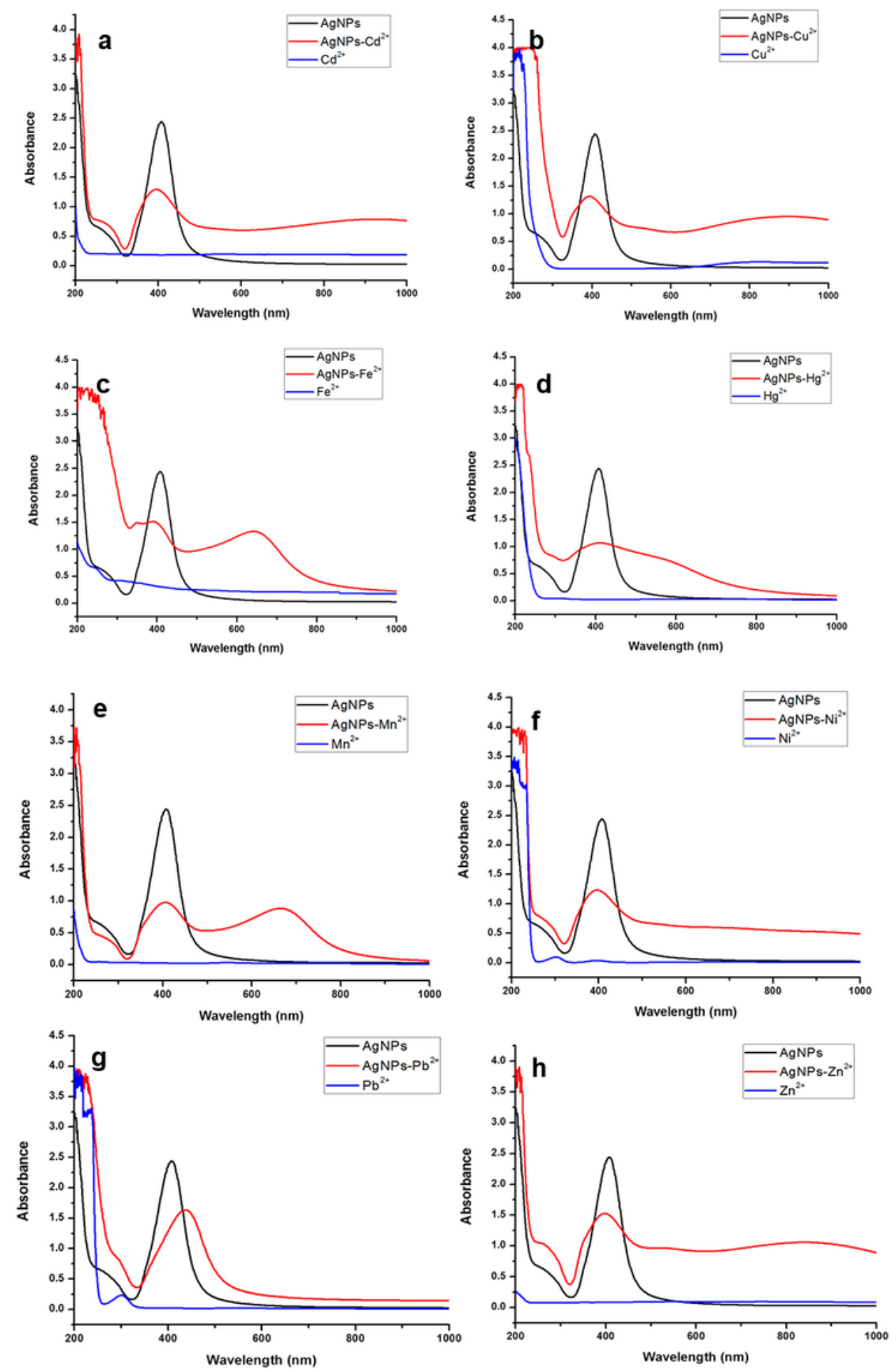

\section{Figure 4}

UV-Vis spectra of before and after addition of AgNPs with metal ions solutions interaction (a) $\mathrm{Cd}^{2+}$; (b) $\mathrm{Cu}^{2+} ;$ (c) $\mathrm{Fe}^{2+}$; (d) $\mathrm{Hg}^{2+}$; (e) $\mathrm{Mn}^{2+}$; (f) $\mathrm{Ni}^{2+} ;$ (g) $\mathrm{Pb}^{2+}$ and (h) $\mathrm{Zn}^{2+}$ 


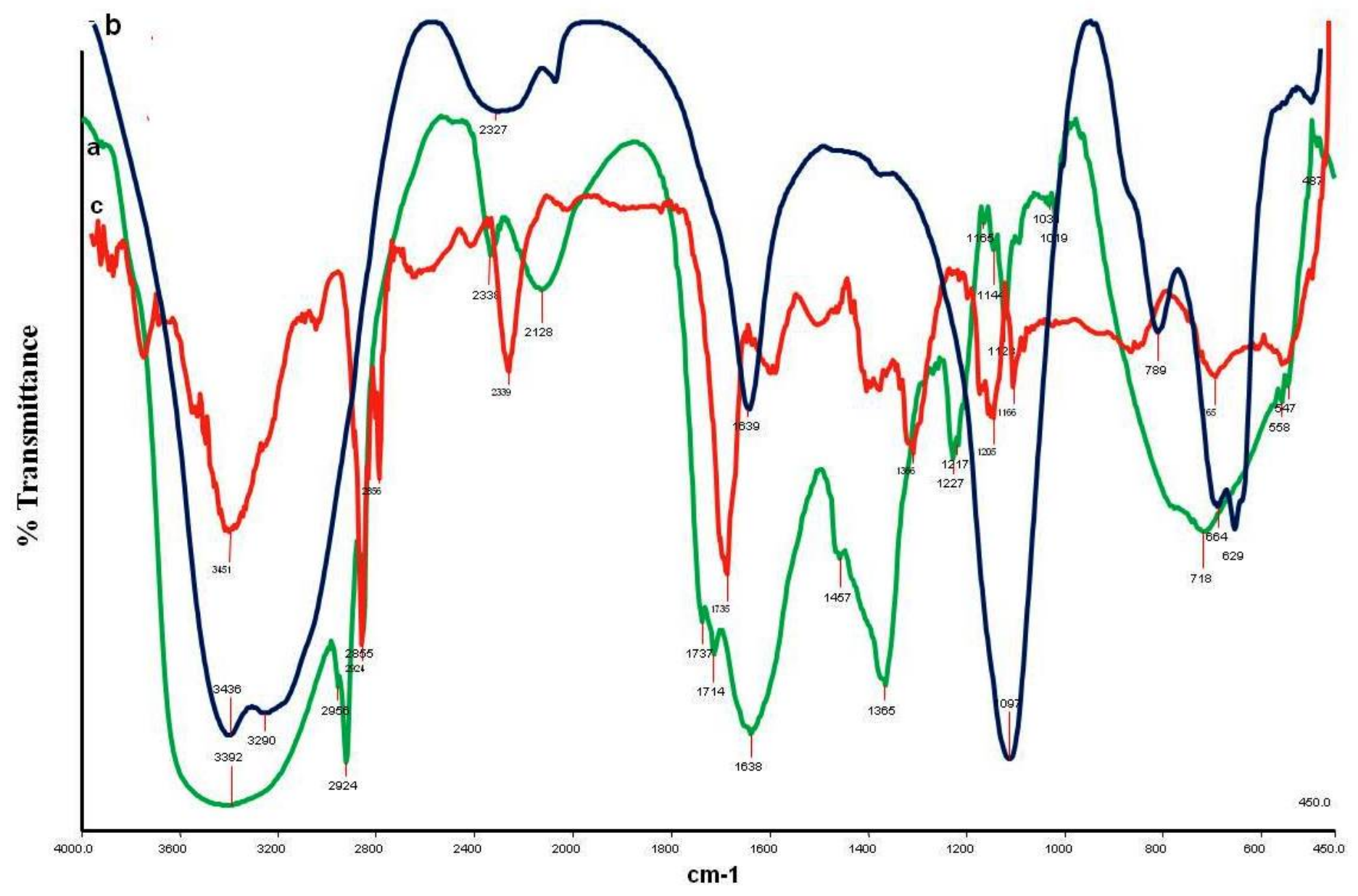

Figure 5

FT-IR spectra of (a) AgNPs; (b) $\mathrm{CdSO}_{4}$ metal salt and (c) AgNPs interaction with $\mathrm{Cd}^{2+}$ metal ion 


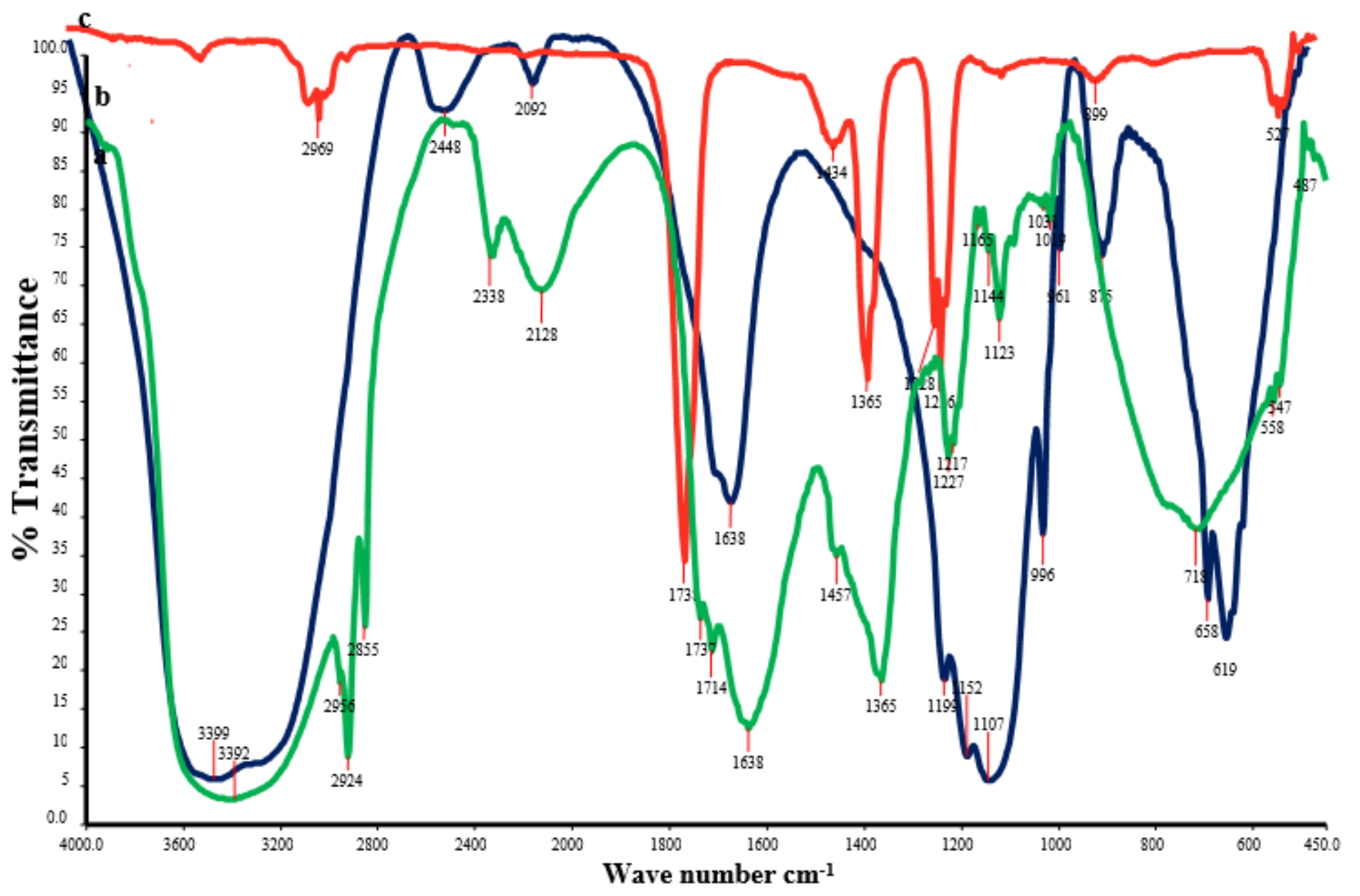

Figure 6

FT-IR spectra of (a) AgNPs; (b) $\mathrm{CuSO}_{4}$ metal salt; (c) AgNPs interaction with $\mathrm{Cu}^{2+}$ metal ion 


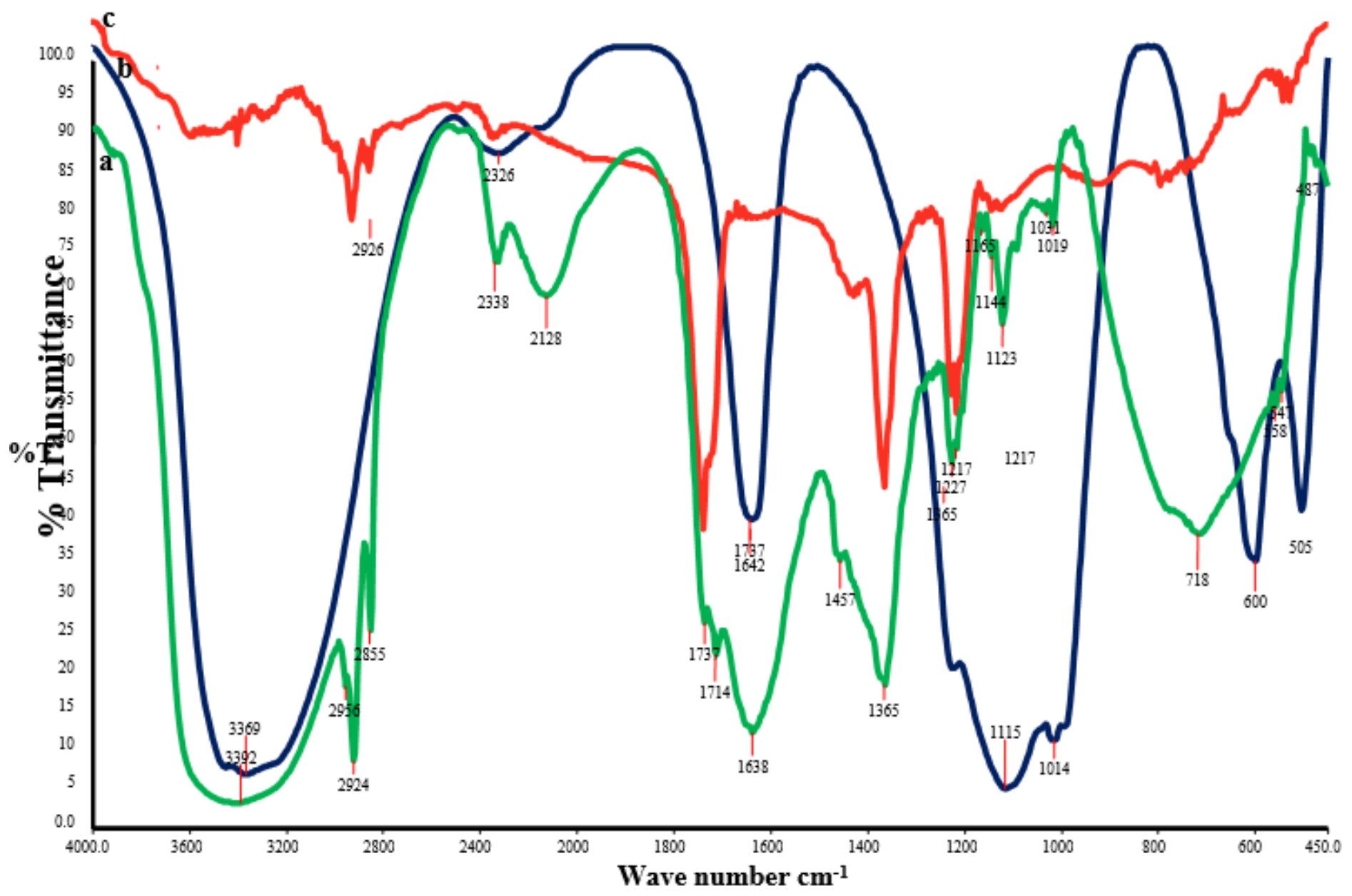

Figure 7

FT-IR spectra of (a) AgNPs; (b) $\mathrm{FeSO}_{4}$ metal salt and (c) AgNPs interaction with $\mathrm{Fe}^{2+}$ metal ion 


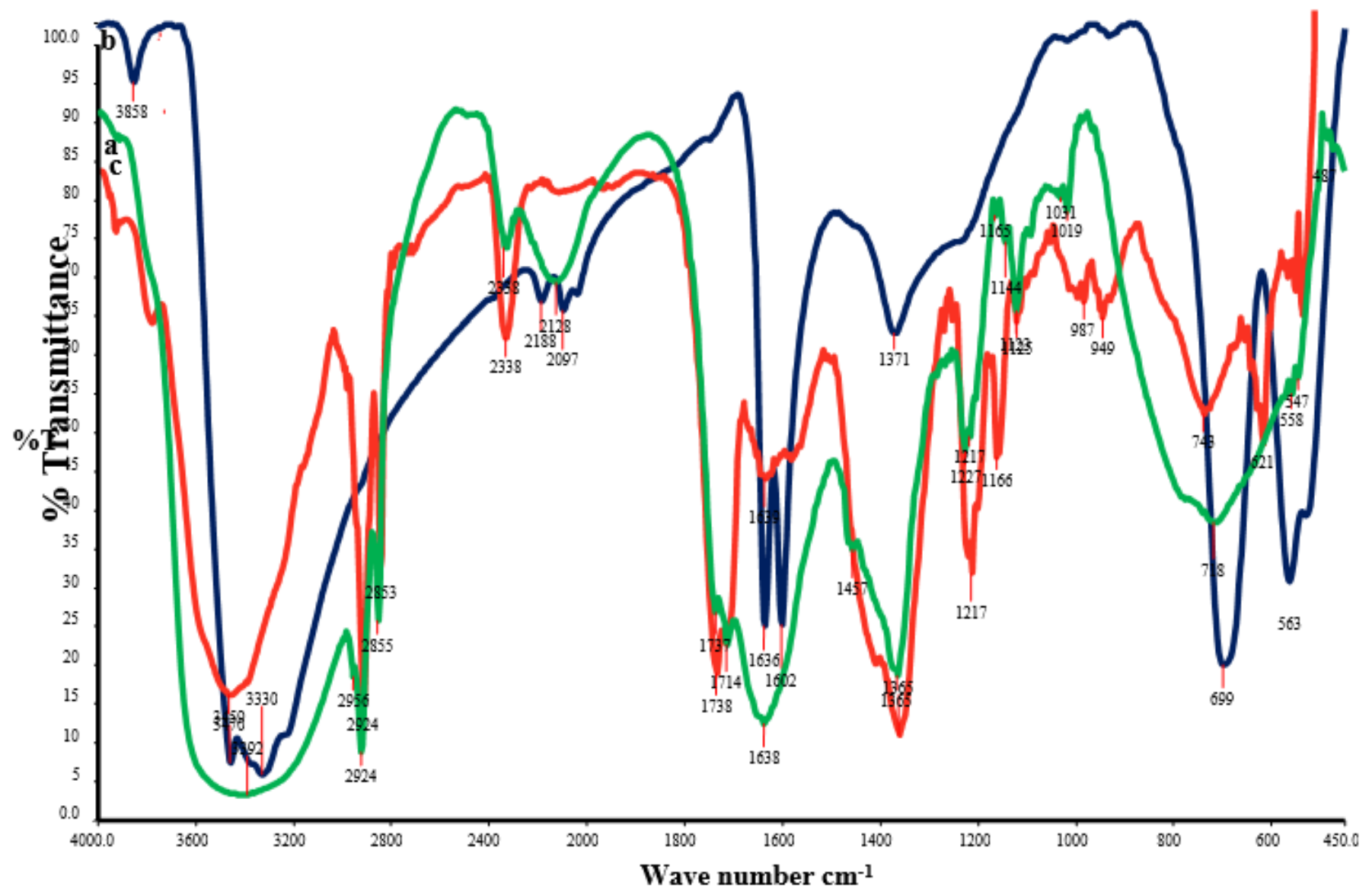

Figure 8

FT-IR spectra of (a) AgNPs; (b) $\mathrm{HgCl}_{2}$ metal salt and (c) AgNPs interaction with $\mathrm{Hg}^{2+}$ metal ion 


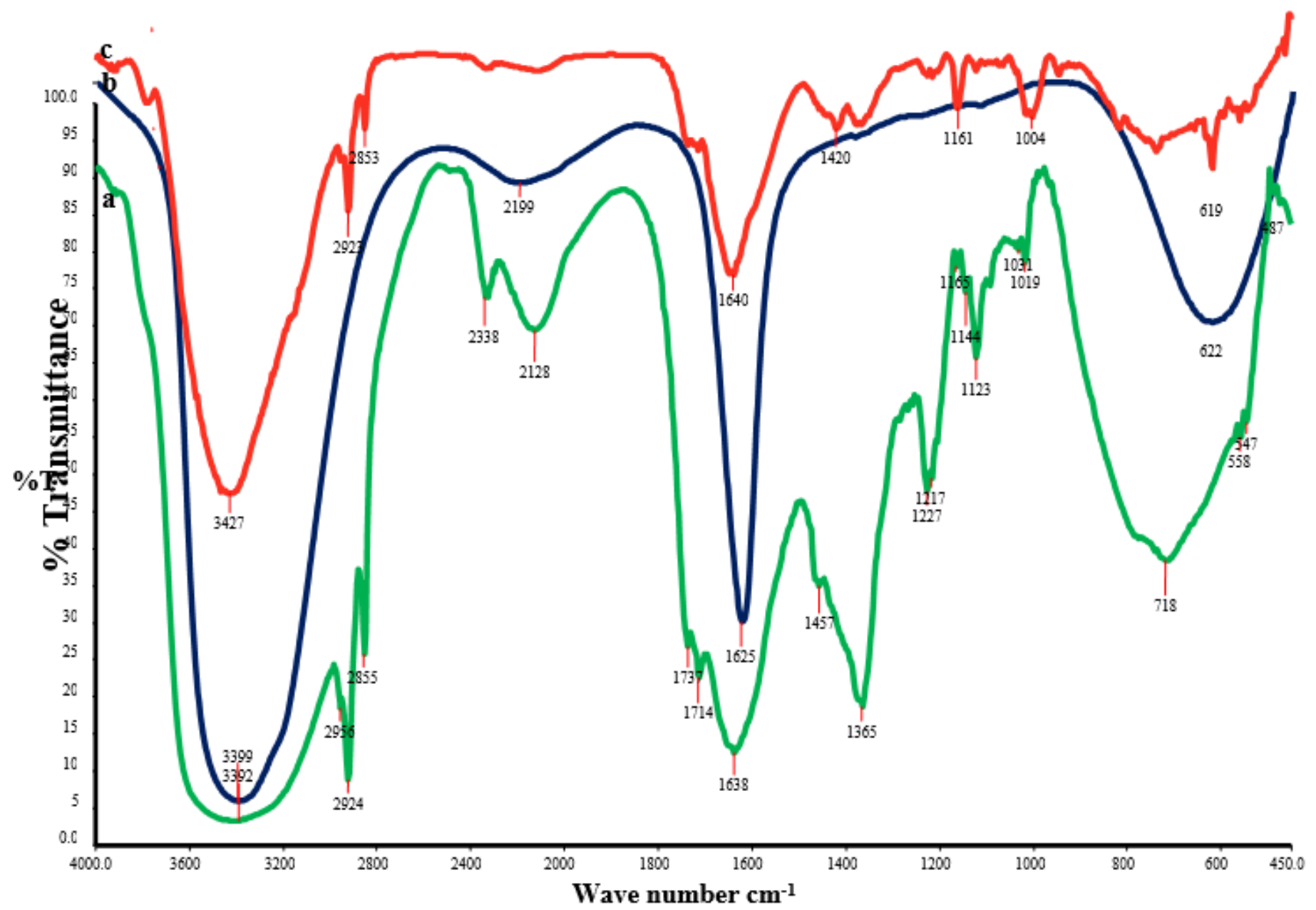

Figure 9

FT-IR spectra of (a) AgNPs; (b) $\mathrm{MnCl}_{2}$ metal salt and (c) AgNPs interaction with $\mathrm{Mn}^{2+}$ metal ion 


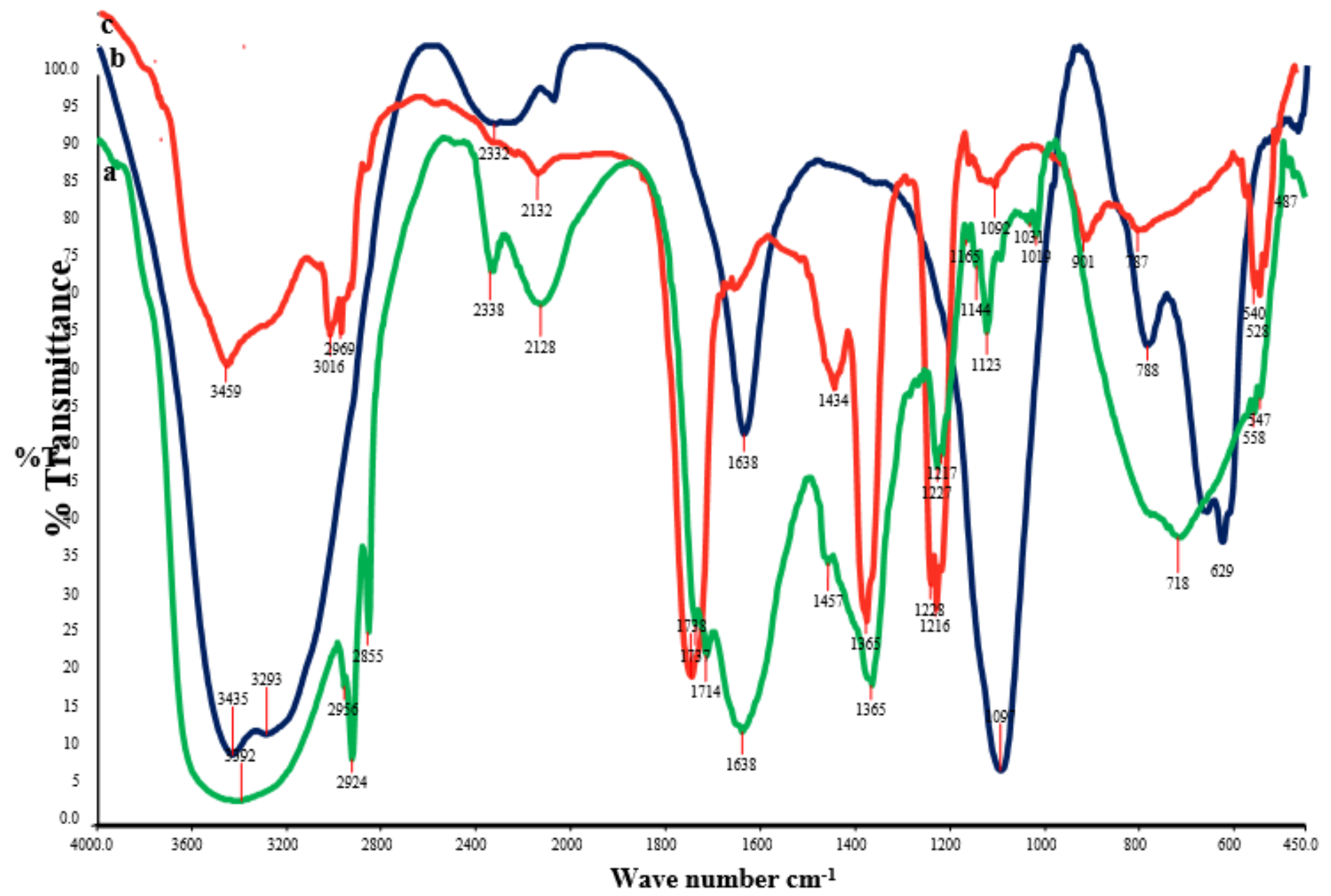

Figure 10

FT-IR spectra of (a) AgNPs; (b) $\mathrm{NiSO}_{4}$ metal salt and (c) AgNPs interaction with $\mathrm{Ni}^{2+}$ metal ion 


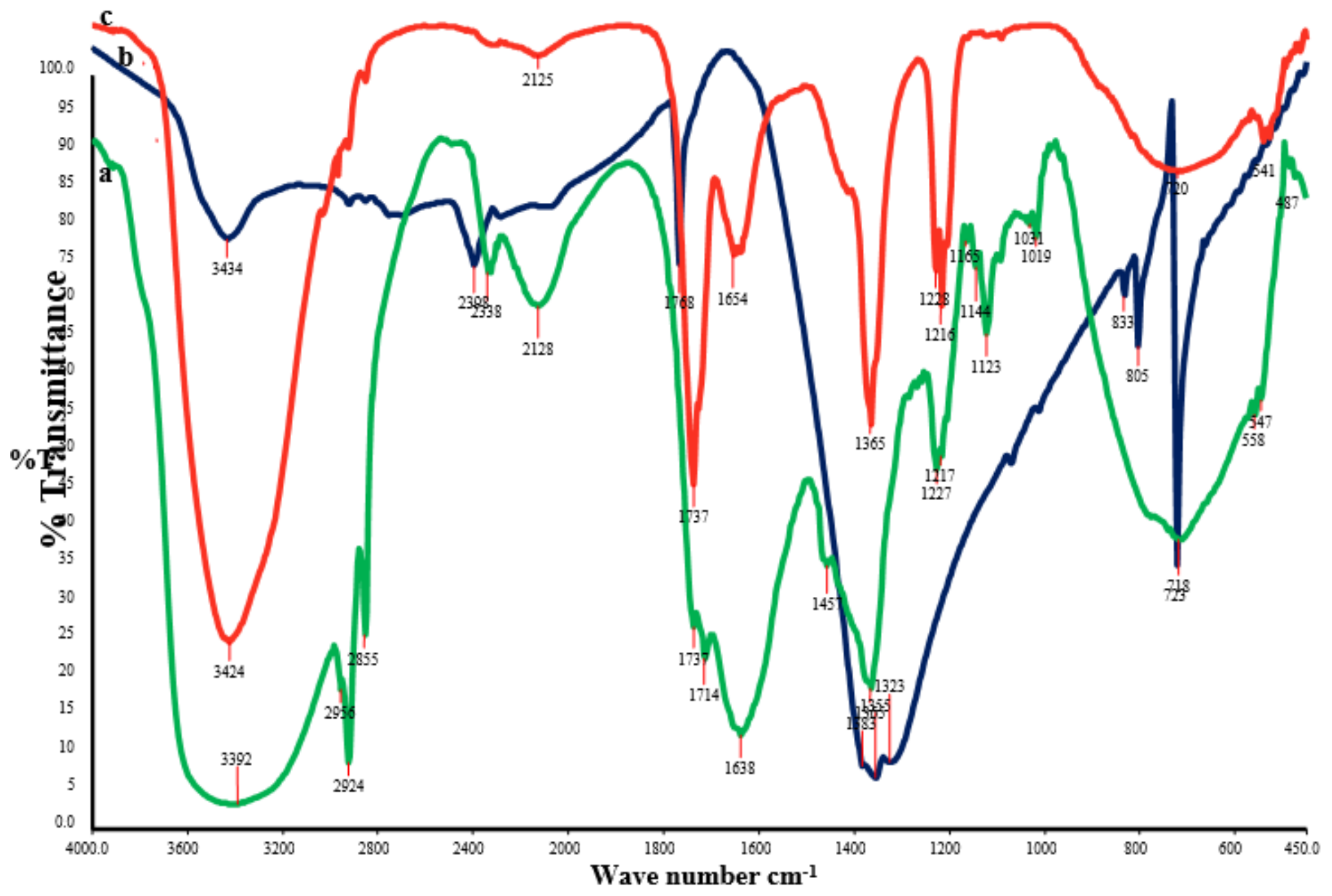

Figure 11

FT-IR spectra of (a) AgNPs; (b) $\mathrm{Pb}(\mathrm{NO})_{3}$ metal salt and (c) AgNPs interaction with $\mathrm{Pb}^{2+}$ metal ion 


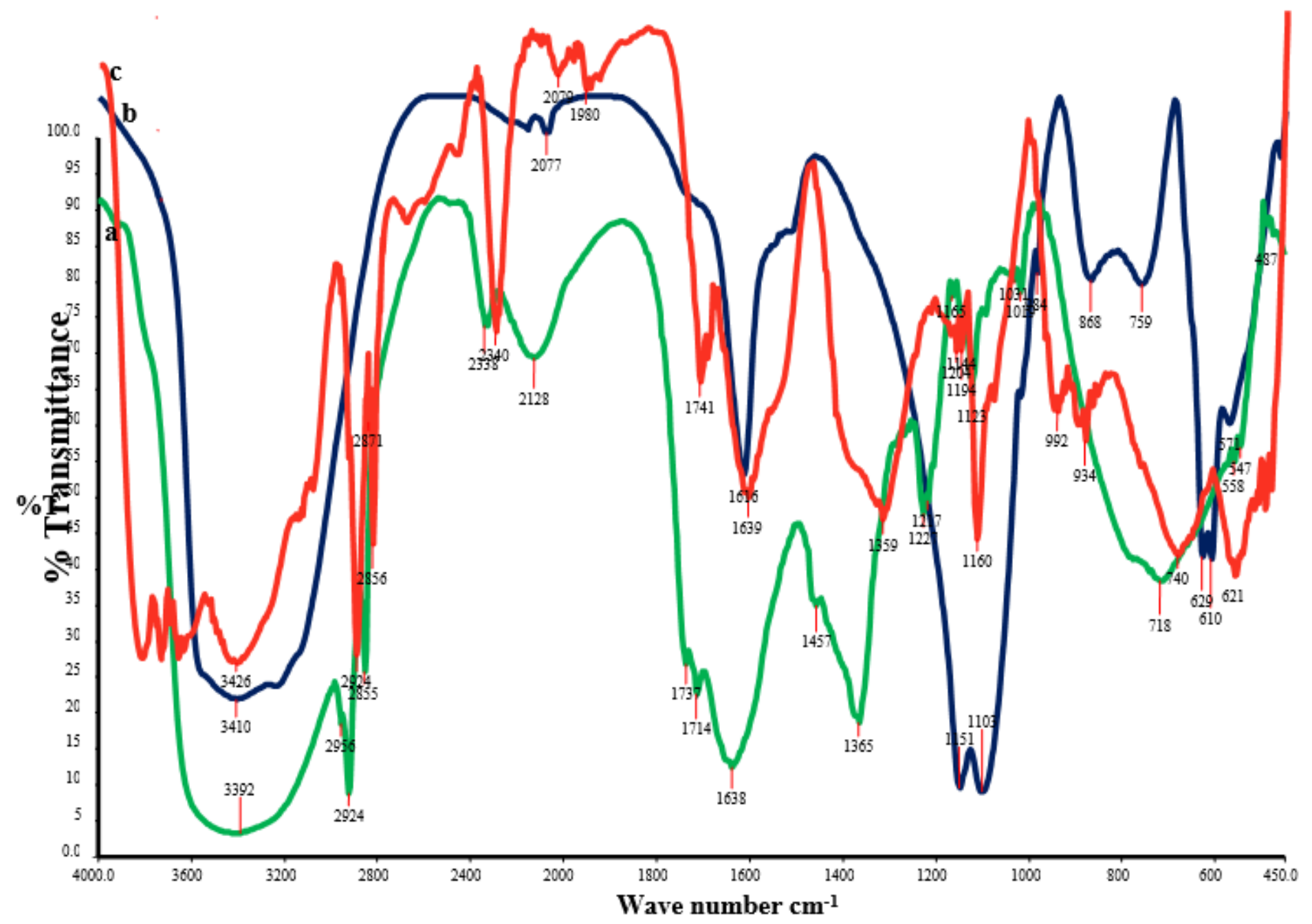

Figure 12

FT-IR spectra of (a) AgNPs; (b) $\mathrm{ZnSO}_{4}$ metal salt and (c) AgNPs interaction with $\mathrm{Zn}^{2+}$ metal ion 


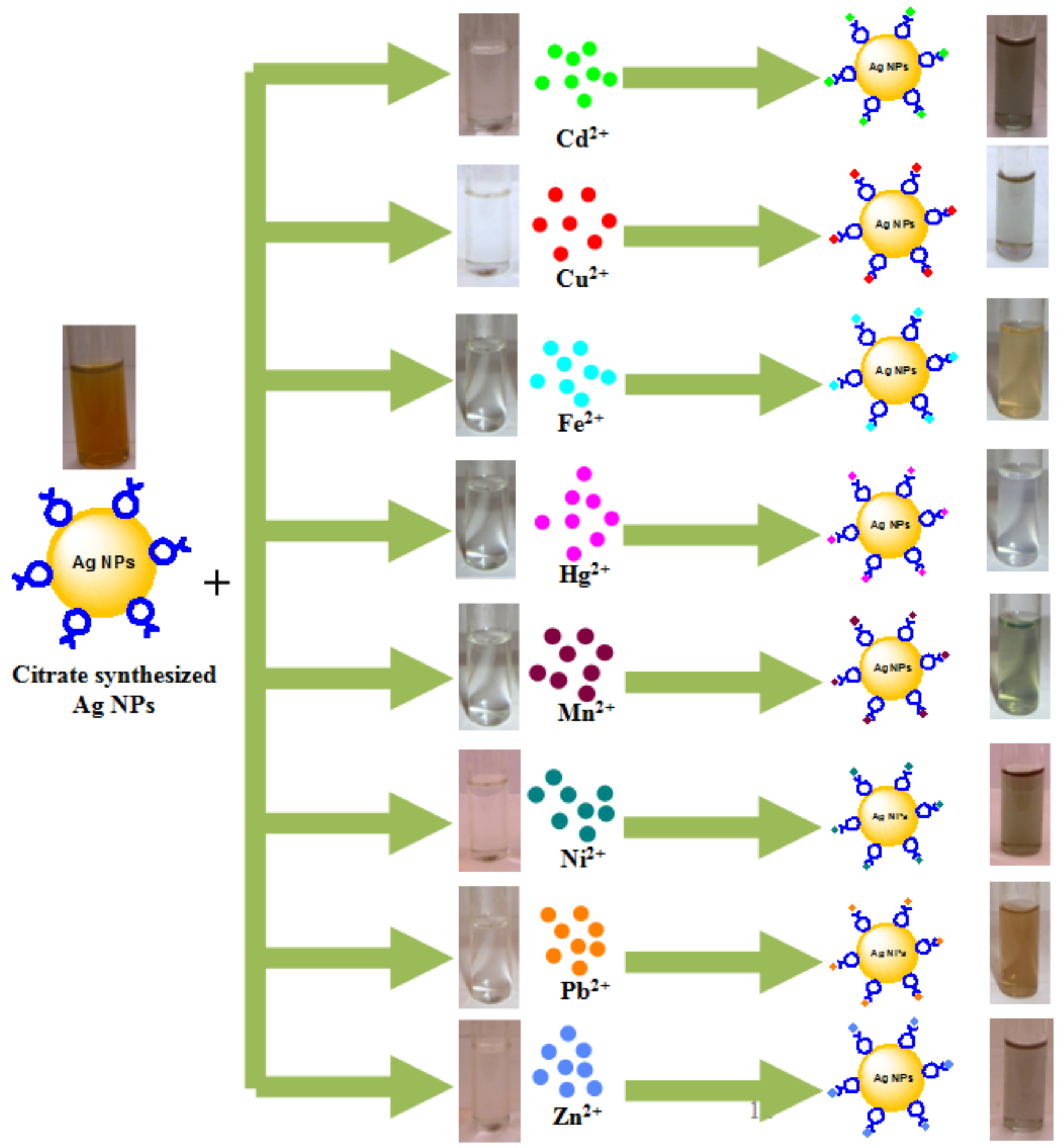

Figure 13

Schematic illustration of Ag nanoparticles interaction with metal ions 